\title{
Evidence that the Serum Resistance Genetic Locus sac-3 of Neisseria gonorrhoeae Is Involved in Lipopolysaccharide Structure
}

\author{
By DAVID S. STEPHENS ${ }^{1}$ * AND WILliAM M. SHAFER ${ }^{2}$ \\ $V A$ Medical Center and Departments of Medicine ${ }^{1}$ and Microbiology and Immunology ${ }^{2}$, Emory \\ University School of Medicine, Atlanta, Georgia 30322, USA
}

(Received 17 February 1987; revised 6 May 1987)

\begin{abstract}
The gonococcal chromosome contains a sequence of closely linked genes (for example, sac-1, $s a c-3, n m p)$ known or presumed to affect cell envelope structure and which appear to influence susceptibility of gonococci to killing by normal human sera (NHS). Previous work has shown that the serum-resistant isolate FA19, and FA899, a serum-sensitive transformant of FA19, differ in outer membrane protein I (PI) and at the sac-3 genetic locus. However, the sac-3 locus is separable from changes determined by $n m p-3$, the gene determining PI species. We found that FA19 and FA899 differ in lipopolysaccharide (LPS) molecular size and in reactivity with a monoclonal antibody which recognizes an LPS (L8) epitope. To address the question of whether the changes in LPS were due to the sac-3 locus, we constructed new transformants of FA19 using donor DNA prepared from FA899. The new transformants could be divided into three groups: (1) those identical to FA19 in serum resistance ( $>90 \%$ survival at $120 \mathrm{~min}$ ), in LPS molecular size and in expression of the L8 epitope; (2) those identical to FA899 in serum sensitivity $(100 \%$ killed at $30 \mathrm{~min}$ ), in LPS molecular size and in lack of expression of the L8 epitope; (3) those significantly killed by $50 \%$ NHS at $120 \mathrm{~min}$, whose LPS molecular size was greater than that of FA19 but less than that of FA899 and which did not express the L8 epitope. Except for PI there were no differences in other outer-membrane proteins (e.g. PII, PIII, H.8) among these transformants. Studies of PI using monoclonal antibodies which distinguish between PI serovars confirmed that changes in PI were separate from changes in serum resistance or alteration in LPS chemotype. These data indicate that a genetic locus involved in LPS structure appears to be identical with the sac-3 locus, which influences serum susceptibility in Neisseria gonorrhoeae.
\end{abstract}

\section{INTRODUCTION}

Gonococci isolated from patients with disseminated gonococcal infections are typically resistant to complement-mediated killing by normal human serum (NHS) (Schoolnik et al., 1976). In contrast, strains isolated from patients with uncomplicated gonococcal infections tend to be sensitive to NHS (Brooks \& Ingwer, 1978). The molecular basis of serum resistance of gonococci remains unknown. Nevertheless, at least two closely linked genes termed sac-1 and sac-3 (sac: serum antibody complement) have been described (Cannon et al., 1981; Shafer et al., 1982). Expression of these loci has been suggested to result in the alteration of the gonococcal cell envelope providing for serum resistance $\left(\mathrm{Sac}^{\mathrm{r}}\right)$.

Gene products of $s a c-1$ and $s a c-3$ providing for $\mathrm{Sac}^{r}$ have not been described. Genetic studies (Cannon et al., 1981; Shafer et al., 1982) have separated sac-1 and sac-3 from $\mathrm{nmp}$ (new membrane protein) loci involved in PI synthesis; alterations in PI had earlier been thought to be responsible for $\mathrm{Sac}^{\mathrm{r}}$ (Hildebrandt et al., 1978). Changes in lipopolysaccharide (LPS) structure

\footnotetext{
Abbreviations: Mab, monoclonal antibody; NHS, normal human sera/serum; PI, gonococcal outer-membrane protein $\mathrm{I}$.
} 
have also been associated with $\mathrm{Sac}^{\mathrm{r}}$ because spontaneous LPS mutants deficient in core oligosaccharides of Sacr strain FA19 were found to be Sac (Guymon et al., 1982). In this study we show that the gene for an LPS epitope associated with $\mathrm{Sac}^{\mathrm{r}}$ appears identical to $s a c-3$ and distinct from a locus (nmp-3) involved in PI synthesis, and describe new genetic and biochemical studies to show that $s a c-3$ strains differ from $s a c-3^{+}$strains in LPS.

\section{METHODS}

Gonococcal strains. The strains of Neisseria gonorrhoeae used and their genetic construction are listed in Table 1. Strain FA19 (sac-1 sac-3) has been well characterized (Cannon et al., 1981; Sparling et al., 1975). We refer to loci dictating serum sensitivity to NHS as either $s a c-1^{+}$or $s a c-3^{+}$and the resistant alleles are termed $s a c-1$ or $s a c-3$. Strain FA899 is a sac-3+ transformant of FA19 (Shafer et al., 1982) originally obtained by using DNA from strain FA889 $\left(s a c-3^{+}\right)$, a clinical isolate obtained from Inga Lind at the Statens Serum-Institut, Copenhagen. The PI serovar of these isolates and of the new transformants described herein was kindly determined by Dr Joan Knapp (Centers for Disease Control, Atlanta, GA, USA). Colony type $T_{1}$ (piliated) vs $\mathrm{T}_{4}$ (nonpiliated) and colony opacity were determined by techniques previously described (Stephens et al., 1984).

Serum bactericidal assay (SBA). A microdilution SBA was performed as previously described (Stephens \& McGee, 1983). Briefly, blood from normal adult subjects without a history of gonococcal or meningococcal disease, and not under antibiotic therapy, was collected under sterile conditions, allowed to clot for $30 \mathrm{~min}$ at room temperature $\left(23^{\circ} \mathrm{C}\right)$, and then centrifuged at $500 \mathrm{~g}$ at $4{ }^{\circ} \mathrm{C}$ for $15 \mathrm{~min}$. The serum was removed, divided into subsamples, and stored at $-70^{\circ} \mathrm{C}$ until used in the experiments. Total haemolytic activity in the serum [measured by the $\mathrm{CH}_{50}$ value (amount of complement required to lyse $50 \%$ of sensitized sheep red blood cells)] was at normal levels. Isolates to be tested were grown on GCISO agar plates [GC agar base (BBL) plus $2 \%(\mathrm{v} / \mathrm{v})$ IsovitaleX] (Stephens \& $\mathrm{McGee}, 1983)$ for $14-16 \mathrm{~h}$ at $37^{\circ} \mathrm{C}$ in $3 \%(\mathrm{v} / \mathrm{v}) \mathrm{CO}_{2}$. Inocula $\left(\mathrm{Op}^{-}, \mathrm{Pil}^{-}\right)$were prepared, diluted to the desired concentration and used immediately in the SBA. In some experiments hypogammaglobulinaemic serum from a patient with acquired common variable immunodeficiency or C2-deficient human serum (Cytotech) were used.

Serum $(0.5 \mathrm{ml})$, bacterial inoculum $(0.1 \mathrm{ml})$ and HEPES-MEM $(0.4 \mathrm{ml})$ were mixed so that the final suspension contained $1 \mathrm{ml}$ with $50 \%(\mathrm{v} / \mathrm{v})$ serum and $2 \times 10^{4}$ c.f.u. $\mathrm{ml}^{-1}$. The reaction mixture was incubated at $37^{\circ} \mathrm{C}$ in $3 \%$ $(\mathrm{v} / \mathrm{v}) \mathrm{CO}_{2}$ with end-over-end rotation. Triplicate samples $(0.01 \mathrm{ml})$ were withdrawn from the reaction mixture immediately after preparation and after 15, 30,60 and 120 min incubation. Colony counts were performed as previously described (Stephens \& McGee, 1983). After overnight incubation of the plates, the number of c.f.u. per sample was counted and the number of c.f.u. $\mathrm{ml}^{-1}$ in the original mixture at each sampling time was calculated. Data were expressed as percentage survival. The significance of differences between the means of two variables was determined using Student's $t$-test with unpaired values and a two-tailed hypothesis.

Genetic transformation. Transforming DNA used in these experiments was prepared by the method of Marmur (1961). Transforming DNA was prepared from strain FA899 $\left(\mathrm{sac}-3^{+}\right)$and used to transform strain FA19 (sac-3) by techniques described previously (Shafer et al., 1981). Limiting concentrations $\left(0 \cdot 1 \mu \mathrm{g} \mathrm{ml}^{-1}\right)$ of DNA were used. Spectinomycin resistant $\left(\mathrm{Spc}^{\mathrm{r}}\right)$ transformants were selected using GC base agar overlays containing $100 \mu \mathrm{g}$ spectinomycin $\mathrm{ml}^{-1}$ (Shafer et al., 1982).

Biochemical and immunochemical analysis of gonococcal strains. SDS-PAGE of lysates of whole gonococci was done using $15 \%(\mathrm{w} / \mathrm{v})$ acrylamide gels by techniques previously described (Stephens et al., 1985). Proteinase K digests of the whole cell lysates were prepared (Hitchcock \& Brown, 1983) and the gels were silver stained (Tsai \& Frasch, 1982).

Western immunoblotting was done by a modification of the method of Towbin et al. (1979) as previously described (Stephens et al., 1985). Monoclonal antibody L8, an IgG class immunoglobulin (kindly supplied by Dr Wendell Zollinger, Walter Reed Army Institute of Research) was used in these experiments. L8 recognizes a Neisseria LPS epitope (designated L8) associated with Sacr but not Sac ${ }^{\mathrm{s}}$ gonococcal strains (Schneider et al., 1985). Antibody binding to LPS immobilized on nitrocellulose was detected using staphylococcal protein A conjugated with peroxidase as previously described (Stephens et al., 1985).

\section{RESULTS}

Strain FA19 resists killing by $50 \%$ (v/v) NHS over a 120 min incubation while FA899 is rapidly killed by NHS (Fig. 1). These strains differ in PI molecular mass (Shafer et al., 1982). The results of PI serovar typing (Table 1) and new SDS-PAGE analysis (data not shown) confirmed that these strains differ in PI. Previous studies (Cannon et al., 1981; Shafer et al., 1982) have also shown that differences in PI are unrelated to Sacr since changes in PI could be genetically separated from changes in $\mathrm{Sac}^{\mathrm{r}}$. 


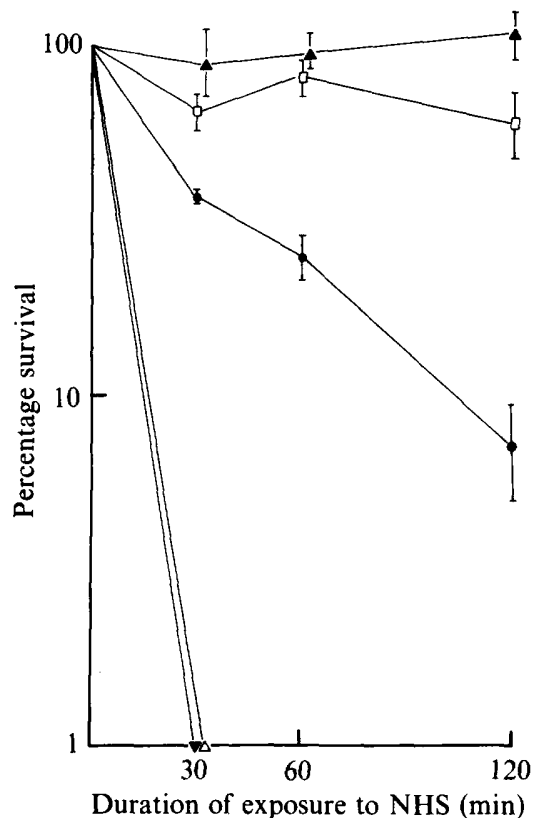

Fig. 1. Serum bactericidal assay ( $50 \%$ NHS) with gonococcal strains FA19, FA899, SS-2, SS-4 and SS9. The data are expressed as percentage survival relative to the 0 time values. Strain FA19 ( $\square$ ) resists killing by NHS over 120 min incubation while FA899 ( $)$ is rapidly killed. Transformant SS-4 (A) resembles FA19 in susceptibility to NHS, while SS-2 $(\triangle)$ resembles FA899. With transformant SS-9 $(\bullet)$, killing occurred in a delayed fashion over a period of $120 \mathrm{~min}$. Data are the means $\pm S E M$ of three or more experiments with each variable.

Table 1. Characteristics of $N$. gonorrhoeae strains and new transformants

\begin{tabular}{|c|c|c|c|c|c|c|c|}
\hline \multirow[b]{2}{*}{ Strain $\dagger$} & \multirow{2}{*}{$\begin{array}{l}\text { Relevant } \\
\text { genotype }\end{array}$} & \multirow{2}{*}{$\begin{array}{c}\text { Relevant } \\
\text { phenotype§ }\end{array}$} & \multicolumn{2}{|c|}{$\begin{array}{c}\text { Serum bactericidal } \\
\text { assay } \\
(\% \text { survival })\end{array}$} & \multirow{2}{*}{$\begin{array}{c}\text { PI } \\
\text { serovar }\end{array}$} & \multirow{2}{*}{$\begin{array}{l}\text { L8 LPS } \\
\text { epitope }\end{array}$} & \multirow{2}{*}{$\begin{array}{c}\text { LPS } \\
\text { molecular } \\
\text { size } \\
(\mathrm{kDa})\end{array}$} \\
\hline & & & $30 \mathrm{~min}$ & $120 \mathrm{~min}$ & & & \\
\hline $\begin{array}{l}\text { FA19 } \\
\text { FA889 } \\
\text { FA899 }\end{array}$ & $\begin{array}{l}s p c-4^{+} \text {sac-1 } s a c-3 \\
s p c-4 \text { sac-1 sac-3+ } \\
\text { spc-4 sac-1 } s a c-3^{+}\end{array}$ & $\begin{array}{l}\mathrm{Spc}^{\mathrm{s}} \mathrm{Sac}^{\mathrm{r}} \\
\mathrm{Spc}^{\mathrm{r}} \mathrm{Sac}^{\mathrm{s}} \\
\mathrm{Spc}^{r} \mathrm{Sac}^{\mathrm{s}}\end{array}$ & $\begin{array}{r}69 \\
0 \\
0\end{array}$ & $\begin{array}{r}78 \\
0 \\
0\end{array}$ & $\begin{array}{l}\text { IA } 1 \\
\text { IB9 } \\
\text { IB9 }\end{array}$ & $\begin{array}{l}+ \\
- \\
-\end{array}$ & $\begin{array}{l}5 \cdot 8 \\
6 \cdot 6 \\
6 \cdot 6\end{array}$ \\
\hline SS-1 & $s p c-4$ sac-1 sac-3 & $\operatorname{Spc}^{r} \operatorname{Sac}^{r}$ & 71 & $>100$ & IAI & + & $5 \cdot 8$ \\
\hline SS-2 & $s p c-4$ sac-1 sac-3+ & $\mathrm{Spc}^{\mathrm{r}} \mathrm{Sac}^{\mathrm{s}}$ & 0 & 0 & IB9 & - & 6.6 \\
\hline SS-3 & $s p c-4$ sac-1 sac-3 & $\mathrm{Spc}^{r} \mathrm{Sac}^{r}$ & 83 & $>100$ & IB9 & + & $5 \cdot 8$ \\
\hline SS-4 & $s p c-4$ sac-1 sac-3 & $\operatorname{Spc}^{r} \mathrm{Sac}^{r}$ & 89 & $>100$ & IA1 & + & $5 \cdot 8$ \\
\hline SS-5 & $s p c-4$ sac-1 sac-3 & $\operatorname{Spc}^{r} \operatorname{Sac}^{r}$ & 63 & $>100$ & IAI & + & $5 \cdot 8$ \\
\hline SS-6 & $s p c-4$ sac-1 sac-3 & $\mathrm{Spc}^{r} \mathrm{Sac}^{r}$ & 68 & 70 & IB9 & + & $5 \cdot 8$ \\
\hline SS-7 & $s p c-4$ sac-1 sac-3 & $\mathrm{Spc}^{r} \mathrm{Sac}^{r}$ & 68 & $>100$ & IA 1 & + & $5 \cdot 8$ \\
\hline SS-8 & $s p c-4$ sac-1 sac-3+ & $\mathrm{Spc}^{r} \mathrm{Sac}^{\mathrm{s} *}$ & 35 & 10 & IB9 & - & $6 \cdot 2$ \\
\hline SS-9 & $s p c-4$ sac-1 sac-3+ & $\mathrm{Spc}^{r} \mathrm{Sac}^{\mathrm{s*}}$ & 37 & 7 & IB9 & - & $6 \cdot 2$ \\
\hline SS-10 & $s p c-4$ sac-1 sac- $3^{+}$ & $\mathrm{Spc}^{\mathrm{r}} \mathrm{Sac}^{\mathrm{s*}}$ & 36 & 14 & IB9 & - & $6 \cdot 2$ \\
\hline SS-11 & spc-4 sac-1 sac- $3^{+}$ & $\mathrm{Spc}^{r} \mathrm{Sac}^{\mathrm{s*}}$ & 30 & 6 & IB9 & - & $6 \cdot 2$ \\
\hline SS-12 & spc-4 sac-1 sac-3+ & $\mathrm{Spc}^{r} \mathrm{Sac}^{\mathrm{s*}}$ & 38 & 18 & IB9 & - & $6 \cdot 2$ \\
\hline SS-13 & $s p c-4$ sac-1 sac-3 & $\mathrm{Spc}^{r} \mathrm{Sac}^{\mathrm{r}}$ & 57 & 92 & IA I & + & $5 \cdot 8$ \\
\hline SS-14 & $s p c-4$ sac-1 sac-3 & $\operatorname{Spc}^{r} \mathrm{Sac}^{r}$ & 52 & $>100$ & IB9 & + & $5 \cdot 8$ \\
\hline
\end{tabular}

† Strains SS-1 to SS-14 were derived by transformation of strain FA19 with DNA from strain FA899.

$\ddagger s a c$, serum-antibody-complement resistant; spc-4, spectinomycin resistant (+ indicates a sensitive allele). $\S \mathrm{Sac}^{\mathrm{r}}$, resistant to killing by $50 \%$ NHS; Sac ${ }^{\text {s }}$, sensitive to killing by $50 \%$ NHS at $<30 \mathrm{~min}$; Sac ${ }^{\text {s* }}$, sensitive to killing by $50 \%$ NHS at $120 \mathrm{~min}$. 

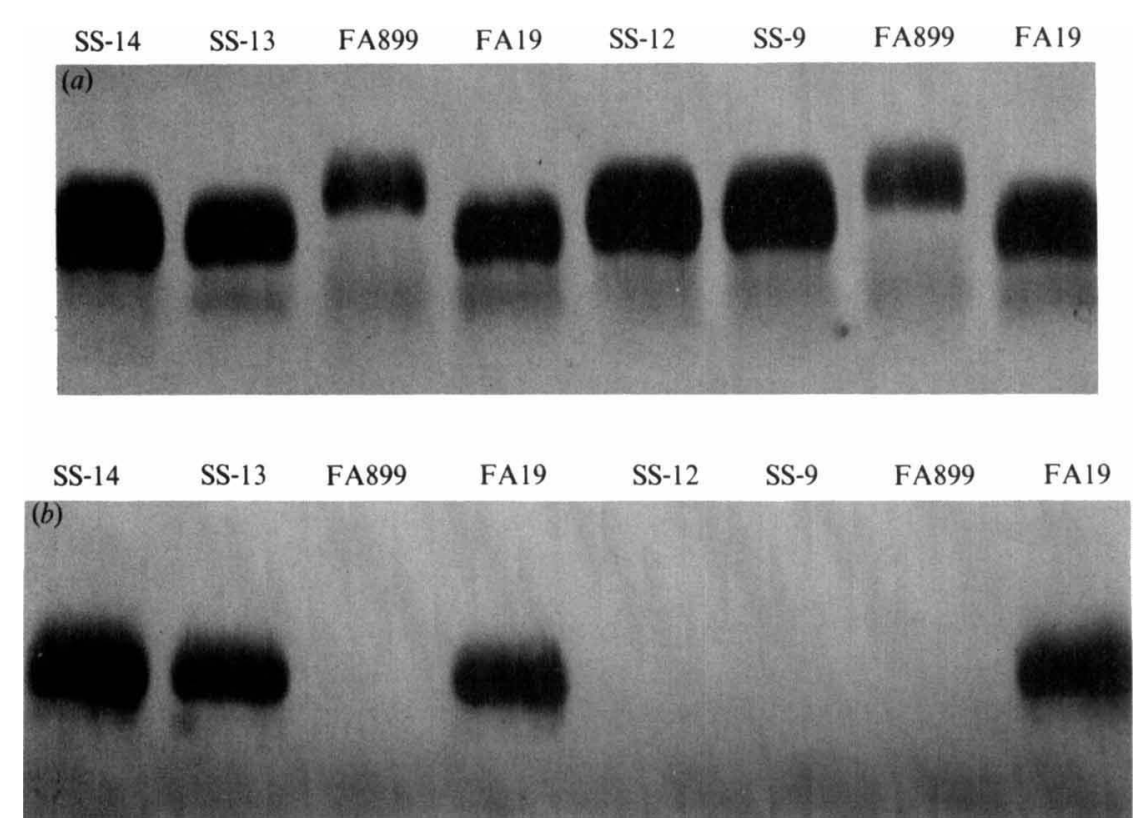

Fig. 2. (a) SDS-PAGE (15\% acrylamide gel) of proteinase-K-digested whole-cell lysates of gonococcal strains SS-14, SS-13, FA899, FA19, SS-12, SS-9, FA899 and FA19. SS-14 and SS-13 are Sacr transformants which have the same LPS molecular size $(\sim 5.8 \mathrm{kDa})$ as the Sac ${ }^{\mathrm{r}}$ parent FA19. SS-12 and SS-9 are Sac ${ }^{* *}$ transformants whose LPS differs in molecular size $(\sim 6.2 \mathrm{kDa})$ from the LPS of FA19 $(\sim 5.8 \mathrm{kDa})$ or the $\mathrm{Sac}^{\mathrm{s}}$ transformant FA899 $(\sim 6.6 \mathrm{kDa})$. Similar results were seen with the other Sac and Sac ${ }^{\text {** }}$ transformants. The molecular size of the LPS was calculated in separate experiments using low-molecular-weight protein standards (BRL) and Re, Rd and smooth Salmonella minnesota mutants.

(b) Western immunoblot of the electrophoresed lysates in $(a)$, probed with Mab L8. The Sac transformants SS-13 and SS-14, and FA19, express the L8 LPS epitope while the Sac ${ }^{\text {** }}$ transformants

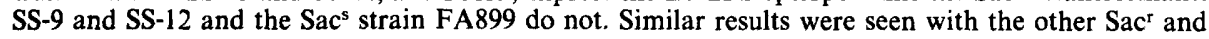
Sac $^{* *}$ transformants.

Differences in LPS have not been previously noted between these strains (Shafer et al., 1982). However, as shown in Fig. 2(a) we found, using techniques developed for examination of LPS by SDS-PAGE (Hitchcock \& Brown, 1983), that FA19 and FA899 differed in LPS molecular size. FA19 and FA899 also differ in the capacity of Mab L8 to recognize their respective LPS in Western immunoblots (Fig. $2 b$ and Table 1). This result suggested that the presence of a genetic determinant closely linked or identical to $s a c-3$ is involved in the synthesis of LPS from Sacr strain FA19.

In order to substantiate the presence of an LPS biosynthetic gene in the $s a c-3^{+}$region, DNA was prepared from strain FA899 and used to transform strain FA19. Spcr transformants were selected since $s a c-3^{+}$cotransforms with $s p c-4$ (Shafer et al., 1982). Fourteen Spc ${ }^{r}$ transformants (SS 1-14) of FAl9 were studied for changes in serum susceptibility, LPS molecular size, reactivity with Mab L8, outer-membrane proteins, and PI serovar. As shown in Table 1 and Fig. $1, \mathrm{Sac}^{\mathrm{r}}$ (>90\% survival at $\left.120 \mathrm{~min}\right), \mathrm{Sac}^{\mathrm{s}}(100 \%$ killed at $30 \mathrm{~min})$ and $\mathrm{Sac}^{\mathrm{s*}}(>90 \%$ killed at $120 \mathrm{~min}$ ) transformants were obtained. Inocula of the parental Sac ${ }^{r}$ strain FA19 and the Sac ${ }^{r}$ transformants exhibited some killing ( $<50 \%$ of inoculum) at $30 \mathrm{~min}$ in $50 \%$ (v/v) NHS. However, by $120 \mathrm{~min}$ multiplication of these strains was occurring, with colony counts occasionally increasing to $>100 \%$ of the initial inoculum. The Sacs transformant SS-2, like the donor strain FA899, was rapidly killed. Data from earlier time points (not shown) indicated that killing of these strains was rapid, within $15 \mathrm{~min}$ of beginning the experiment. Other transformants (e.g. SS-9) displayed intermediate susceptibility to $50 \%$ NHS (Sac ${ }^{5 *}$ ). Killing of $\mathrm{Sac}^{\mathrm{s*}}$ transformants occurred in a delayed fashion over a period of $120 \mathrm{~min}$ (Fig. 1). 


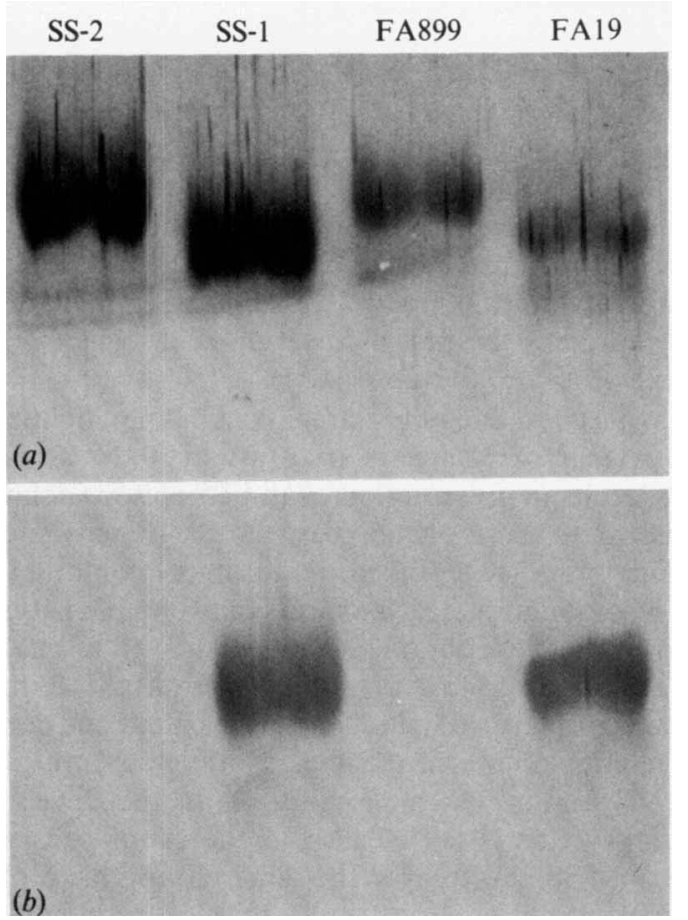

Fig. 3

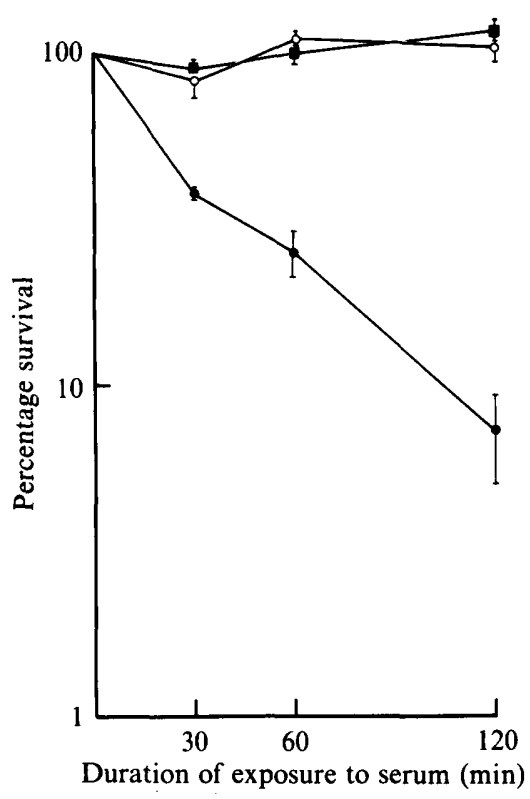

Fig. 4

Fig. 3. SDS-PAGE $(a)$ and Western immunoblot, probed with Mab L8 $(b)$, of proteinase-K-digested whole-cell lysates of gonococcal strains SS-2, SS-1, FA889 and FA19. The Sac transformant SS-2 has the same LPS molecular size as FA899 and does not express the L8 epitope.

Fig. 4. Serum bactericidal assay using 50\% NHS (๑), 50\% hypogammaglobulinaemic serum (ם) or $50 \%$ C2-deficient serum (O), and gonococcal strain SS-9 $\left(\mathrm{Sac}^{\mathrm{s}}\right)$. SS-9 is significantly killed by NHS at $120 \mathrm{~min}$ but is resistant to killing by the other two sera. Data are expressed as the means \pm SEM of three or more experiments with each variable.

All Sac ${ }^{r}$ transformants exhibited an LPS molecular size $(\sim 5.8 \mathrm{kDa})$ and $\mathrm{L} 8$ reactivity profile like that of FA19 (Table 1, Fig. 2). The Sac ${ }^{s}$ transformant (SS-2) had an LPS molecular size $(\sim 6.6 \mathrm{kDa})$ identical to the donor strain FA899 and failed to react with the L8 Mab (Table 1, Fig. 3). The molecular size ( $\sim 6 \cdot 2 \mathrm{kDa})$ of LPS from the transformants of intermediate serum sensitivity $\left(\mathrm{Sac}^{\mathrm{s} *}\right)$ was distinct from that of FA19 and FA899 (Fig. 2a). LPS from Sac ${ }^{* *}$ transformants failed to react with L8 Mab (Fig. $2 b$ ).

All Sac ${ }^{\mathrm{s}}$ and Sac ${ }^{\mathrm{s} *}$ transformants retained the PI serovar (1B9) of the donor, yet serovar 1B9 transformants (3/8) were recovered from transformants which remained Sac ${ }^{\mathrm{r}}$ and reacted with Mab L8 in Western blots (Table 1). The remaining Sac ${ }^{r}$ transformants were PI serovar IAl. Except for PI no differences in other outer-membrane proteins (e.g. PII, PIII) were noted by SDS-PAGE. The molecular mass of antigen H. 8 of FA19, FA899 and transformants SS-1 to SS14 was also identical as determined in Western immunoblots by monoclonal antibody (kindly supplied by Dr J. Cannon, University of North Carolina).

In order to investigate the mechanism of killing of the intermediate transformants (antibodydependent or -independent, alternative or classical activation of complement) hypogammaglobulinaemic human serum and C2-deficient human serum were used (Fig. 4). The Sac ${ }^{\text {** }}$ transformant SS- 9 was resistant to killing by both these sera at $120 \mathrm{~min}$, in contrast to significant killing in NHS at 120 min. This suggests that the killing of strain SS-9 is by an antibodydependent, classical pathway. 


\section{DISCUSSION}

In this study we show that a genetic determinant involved in LPS structure appears to be $s a c-3$. This area of the gonococcal chromosome in Sac ${ }^{r}$ strain FA19 has been previously associated with the synthesis of cell envelope structures thought to contribute to the $\mathrm{Sac}^{r}$ phenotype (Cannon et al., 1981; Shafer et al., 1982). The well-described sac-1 locus (Cannon et al., 1981), which also gives a Sacr phenotype, is in this region. We were able to separate expression of $s a c-1$ from $s a c-3$ by using high concentrations of NHS (Shafer et al., 1982) and by noting in the current study that in isogenic strains differing at $s a c-1^{+}$, reactivity with Mab L8 was identical (data not shown). Our studies represent the first delineation of a locus (sac-3) involved in LPS structure in this region of the gonococcal chromosome.

This work substantiates earlier observations that sac-3 and $n m p-3$ are linked but not identical, thus indicating that changes in PI do not always result in changes in susceptibility to NHS. Less clear, however, is whether acquisition of $s a c-3$ results in presentation of an LPS epitope defined by Mab L8. Although we were unable to dissociate these phenotypes, the sac-3 locus and a distinct LPS gene determining L8 reactivity may be closely linked, requiring examination of additional transformants in order to identify recombinants which express only one phenotype. This is particularly important because transformants were obtained which displayed killing by NHS in a delayed fashion. Although such transformants lacked reactivity with Mab L8, they appeared to synthesize an LPS with a molecular size intermediate to that of the parent and donor strains. The molecular basis for this type of recombinant, termed Sac ${ }^{\mathrm{s*}}$, is unknown. It may be indicative of two closely linked loci in $\mathrm{sac}^{-3^{+}}$strains which provide for distinct levels of susceptibility to NHS. It is important to clarify this issue because in the serum-sensitive transformants $\left(\mathrm{Sac}^{\mathrm{s}}, \mathrm{Sac}^{\mathrm{s}}\right.$ ) only one transformant, SS-2, displayed the same phenotypic profile as the donor strain FA899. We are currently examining the possibility that a second gene is responsible for the $\mathrm{Sac}^{\mathrm{s*}}$ phenotype.

It was not surprising that alterations in LPS structure were associated with changes in susceptibility of gonococci to human sera. In Salmonella species, deep rough mutants containing truncated LPS are more serum sensitive than the isogenic smooth parental strains (Muschel \& Larsen, 1980). Similarly, studies of serum-sensitive gonococcal mutants, selected by pyocins, have associated loss of components of LPS core polysaccharides to increased susceptibility to NHS (Guymon et al., 1982; Morse \& Apicella, 1982; Shafer et al., 1984). However, in our study a decrease in LPS molecular size was associated with increasing serum resistance. Recently serum resistance in $N$. gonorrhoeae was shown to be related to the lack of a high molecular mass LPS moiety (Tan et al., 1986). In addition, resistance of certain strains of $N$. gonorrhoeae to the bacteriolytic action of NHS has been shown to result from the absence from their LPS of antigenic loci for the lytic immunoglobulin $M$ that is present in most NHS (Schneider et al., 1982). Taken together these data suggest that a mechanism of serum resistance in $N$. gonorrhoeae may be the loss of LPS epitope(s) recognized by naturally occurring bactericidal antibody.

Using isogenic strains, we confirm and extend this hypothesis. We found that expression of a specific LPS epitope (possibly through loss of components that previously masked this epitope) is related to serum resistance. The L8 LPS epitope has been defined (Schneider et al., 1984, 1985) to be within a $\sim 3.6 \mathrm{kDa}$ component of gonococcal and meningococcal LPS, and to be commonly expressed by $\mathrm{Sac}^{r}$ strains of $N$. gonorrhoeae. In a study of 40 randomly selected normal young adults none had evidence of antibody to this epitope (Schneider et al., 1985). We found that the L8 epitope was expressed by the serum-resistant strain FA19 and by all the Sac transformants, but not by $\mathrm{Sac}^{\mathrm{s}}$ strains.

The lack of expression of the L8 epitope and the intermediate size of LPS in our Sac ${ }^{*}$ transformants, which exhibit delayed killing to $50 \%$ NHS, supports the concept that several alterations in LPS, leading to expression of L8, relate to the ability of gonococci to resist killing by human sera. It is likely that multiple genes are involved in synthesis of gonococcal LPS. The $s a c-3$ locus may code for an enzyme which modifies LPS structure in such a way as to expose the L8 epitope. In order to identify further the mechanism by which sac-3 affects LPS, isolation and sequencing of the gene are required. In addition, studies using a panel of LPS monoclonal 
antibodies are needed to map the loss or gain of epitopes associated with changes in LPS and serum susceptibility.

Both $\mathrm{Sac}^{\mathrm{s}}$ and $\mathrm{Sac}^{\mathrm{s} *}$ transformants appeared to be killed by an antibody-dependent classical pathway mechanism since neither class of transformant exhibited susceptibility to C2-deficient or hypogammaglobulinaemic serum. Thus, the Sac ${ }^{\text {** }}$ phenotype might be due to fewer sites for bactericidal antibody, sites for bactericidal antibody which are partially masked by LPS or outer-membrane proteins, less efficient activation of serum complement or differences in C5b-9 deposition or insertion.

Elucidation of the relationship between expression of $s a c-3$, L8 Mab epitope and the immunological basis for the quantitative differences in $\mathrm{Sac}^{\mathrm{s}}$ in the recombinants will require additional study. However, our data indicate that a genetic locus involved in LPS structure appears to be identical with the sac-3 locus influencing serum susceptibility.

This project was supported in part by the Medical Research Service of the Veteran's Administration, by Public Health Service grant AI-21150 from the National Institute of Allergy and Infectious Diseases and by Cooperative Agreement U50/CCU400841-03 from the Centers for Disease Control.

We would like to thank Anne Whitney and Dr Chandrasekhar Sankaran for excellent technical assistance and Lynne Wilson for typing the manuscript.

\section{REFERENCES}

Brooks, G. F. \& INGWER, I. (1978). Studies on the relationship between serum bactericidal activity and uncomplicated genital infections due to Neisseria gonorrhoeae. Journal of Infectious Diseases 138, 333339.

Cannon, J. G., Lee, T. J., Guymon, L. F. \& Sparling, P. F. (1981). Genetics of serum resistance of Neisseria gonorrhoeae: the sac-1 locus. Infection and Immunity 32, 547-552.

Guymon, L. F., Esser, M. \& Shafer, W. M. (1982). Pyocin-resistant lipopolysaccharide mutants of Neisseria gonorrhoeae: alterations in sensitivity to normal human serum and polymyxin B. Infection and Immunity 36, 541-547.

Hildebrandt, J. F., Mayer, L. W., Wong, S. P. \& Buchanan, T. M. (1978). Neisseria gonorrhoeae acquire a new principal outer membrane protein when transformed to resistance to serum bactericidal activity. Infection and Immunity 20, 267-273.

HITCHCOCK, P. J. \& BRown, T. M. (1983). Morphological heterogeneity among Salmonella lipopolysaccharide chemotypes in silver stained polyacrylamide gels. Journal of Bacteriology 154, 269-277.

MARMUR, J. (1961). A procedure for the isolation of deoxyribonucleic acid from microorganisms. Journal of Molecular Biology 3, 208-218.

Morse, S. A. \& APICELla, M. A. (1982). Isolation of lipopolysaccharide mutant of Neisseria gonorrhoeae: an analysis of antigenic and biologic differences. Journal of Infectious Diseases 145, 206-216.

Muschel, L. H. \& LARSEN, L. F. (1980). The sensitivity of smooth and rough Gram-negative bacteria to the immune bactericidal reaction. Proceedings of the Society for Experimental Biology and Medicine 133, 345-348.

Schneider, H., Griffiss, J. M., Williams, G. D. \& PIER, G. B. (1982). Immunological basis of serum resistance of Neisseria gonorrhoeae. Journal of General Microbiology 128, 13-22.

SChNeIder, H., HAle, T. L., Zollinger, W. D., Seid, R. C., JR, HammaCK, C. A. \& GRIFfis, J. M. (1984).
Heterogeneity of molecular size and antigenic expression within lipooligosaccharides of individual strains of Neisseria gonorrhoeae and Neisseria meningitidis. Infection and Immunity 45, 544-549.

SCHNeIder, H., Griffiss, J. M., MaNdRell, E. E. \& JARVIS, G. A. (1985). Elaboration of 3.6-kilodalton lipooligosaccharide, antibody against which is absent from human sera, is associated with serum resistance of Neisseria gonorrhoeae. Infection and Immunity 50, 672-677.

Schoolnix, G. K., Buchanan, T. M. \& Holmes, K. K. (1976). Gonococci causing disseminated gonococcal infection are resistant to the bactericidal action of normal human sera. Journal of Clinical Investigation 58, $1163-1173$.

Shafer, W. M., Guymon, L. F. \& Sparling, P. F. (1982). Identification of a new genetic site $\left(\mathrm{sac}-3^{+}\right)$in Neisseria gonorrhoeae that affects sensitivity to normal human serum. Infection and Immunity 35, 764-769.

Shafer, W. M., JoIner, K., Guymon, L. F., Cohen, M. S. \& SPARLING, P. F. (1984). Serum sensitivity of Neisseria gonorrhoeae: the role of lipopolysaccharide. Journal of Infectious Diseases 149, 175-183.

Sparling, P. F., Sarubil, F. A. \& Blackman, E. (1975). Inheritance of low-level resistance to penicillin, tetracycline and chloramphenicol in Neisseria gonorrhoeae. Journal of Bacteriology 124, 740-749.

STEPHENS, D. S. \& MCGEE, Z. A. (1983). Association of virulence of Neisseria meningitidis with transparent colony type and low-molecular-weight outer membrane proteins. Journal of Infectious Diseases 147, 282-292.

StePhenS, D. S., Krebs, J. W. \& MCGeE, Z. A. (1984). Loss of pili and decreased attachment to human cells by Neisseria meningitidis and Neisseria gonorrhoeae exposed to subinhibitory concentrations of antibiotics. Infection and Immunity 46, 507-513.

Stephens, D. S., Whitney, A. M., Rothbard, J. \& SchoolnIK, G. W. (1985). Pili of Neisseria meningitidis: analysis of structure and investigation of 
structural and antigenic relationships to gonococcal pili. Journal of Experimental Medicine 161, 15391553.

Tan, E. L., Patel, P. V., Parsons, N. J., Martin, P. M. V. \& SMITH, H. (1986). Lipopolysaccharide alteration is associated with induced resistance of Neisseria gonorrhoeae to killing by human serum. Journal of General Microbiology 132, 14071413.
Towbin, H., Staehelin, T. \& Gordon, J. (1979). Electrophoretic transfer of proteins from polyacrylamide gels to nitrocellulose sheets: procedure and some applications. Proceedings of the National Academy of Science of the United States of America 76, 4350-4354.

Tsai, C. M. \& Frasch, C. E. (1982). A sensitive silver stain for detecting lipopolysaccharides in polyacrylamide gels. Analytical Biochemistry 119, 115-119. 